This item was submitted to Loughborough's Research Repository by the author.

Items in Figshare are protected by copyright, with all rights reserved, unless otherwise indicated.

\title{
Thermal sensitivity to warmth during rest and exercise: a sex comparison
}

\section{PLEASE CITE THE PUBLISHED VERSION}

http://dx.doi.org/10.1007/s00421-014-2875-0

\section{PUBLISHER}

C Springer Berlin Heidelberg

\section{VERSION}

AM (Accepted Manuscript)

\section{LICENCE}

CC BY-NC-ND 4.0

\section{REPOSITORY RECORD}

Gerrett, Nicola, Yacine Ouzzahra, Samantha Coleby, Sam Hobbs, Bernard Redortier, Thomas Voelcker, and George Havenith. 2019. "Thermal Sensitivity to Warmth During Rest and Exercise: A Sex Comparison". figshare. https://hdl.handle.net/2134/14592. 
This item was submitted to Loughborough's Institutional Repository (https://dspace.lboro.ac.uk/) by the author and is made available under the following Creative Commons Licence conditions.

\section{creative
commons}

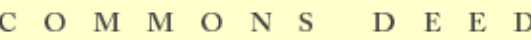

Attribution-NonCommercial-NoDerivs 2.5

You are free:

- to copy, distribute, display, and perform the work

Under the following conditions:

Attribution. You must attribute the work in the manner specified b the author or licensor.

Noncommercial. You may not use this work for commercial purposes.

No Derivative Works. You may not alter, transform, or build upon this work.

- For any reuse or distribution, you must make clear to others the license terms of this work.

- Any of these conditions can be waived if you get permission from the copyright holder.

Your fair use and other rights are in no way affected by the above.

This is a human-readable summary of the Leqal Code (the full license).

\section{Disclaimer 만}

For the full text of this licence, please go to: http://creativecommons.org/licenses/by-nc-nd/2.5/ 


\title{
Thermal sensitivity to warmth during rest and exercise. A sex comparison
}

Authors: Nicola Gerrett ${ }^{13}$, Yacine Ouzzahra ${ }^{1}$, Samantha Coleby ${ }^{1}$, Sam Hobbs ${ }^{1}$, Bernard Redortier ${ }^{2}$, Thomas Voelcker ${ }^{2}$ and George Havenith ${ }^{1}$

${ }^{1}$ Environmental Ergonomics Research Centre, Design School, Loughborough University, Loughborough, Leicestershire, LE113TU, UK.

${ }^{2}$ Oxylane Research, Decathlon Campus, Villeneuve d'Ascq, Lille, France.

${ }^{3}$ Institute of Sport and Exercise Science, University of Worcester, Worcester, United Kingdom.

Corresponding author: George Havenith, Loughborough Design School, Environmental Ergonomics Research Centre, Loughborough University, Loughborough, Leicestershire, LE11 3TU, UK. Email: G.Havenith@lboro.ac.uk

European Journal of Applied Physiology

Title Thermal sensitivity to warmth during rest and exercise: a sex comparison.

\author{
Authors Gerrett N, Ouzzahra Y, Coleby S, Hobbs S, Redortier B, Voelcker T, Havenith G \\ Journal Eur J Appl Physiol
}

Publication date online 08 Apr 2014

DOI $10.1007 / \mathbf{s 0 0 4 2 1 - 0 1 4 - 2 8 7 5 - 0}$ 


\begin{abstract}
Purpose The study aimed to compare thermal sensation in response to a fixed warm stimulus across 31 body locations in resting and active males and females.

Methods Twelve males $\left(20.6 \pm 1.0 \mathrm{yrs}, 78.1 \pm 15.6 \mathrm{~kg}, 180 \pm 8.9 \mathrm{~cm}, 34.4 \pm 5.2 \mathrm{ml} \cdot \mathrm{kg}^{-1} \cdot \mathrm{min}^{-1}\right)$ and 12 females $\left(20.6 \pm 1.4 \mathrm{yrs}, 62.9 \pm 5.5 \mathrm{~kg}, 167 \pm 5.7 \mathrm{~cm}, 36.5 \pm 6.6 \mathrm{ml} \cdot \mathrm{kg}^{-1} \cdot \mathrm{min}^{-1}\right)$ rested in a thermoneutral $\left(22.2 \pm 2.2^{\circ} \mathrm{C}, 35.1 \pm 5.8 \% \mathrm{RH}\right)$ room whilst a thermal probe $\left(25 \mathrm{~cm}^{2}\right)$, set at $40^{\circ} \mathrm{C}$ was applied in a balanced order to 31 locations across the body. Participants reported their thermal sensation 10 seconds after initial application. Following this, participants began cycling at 50\% $\dot{\mathrm{V}} \mathrm{O}_{2 \max }$ for 20 minutes, which was then lowered to $30 \% \dot{\mathrm{V}}{ }_{2 \max }$ and the sensitivity test repeated.
\end{abstract}

Results Females had significantly warmer magnitude sensations than males at all locations $(4.7 \pm 1.8$ vs $3.6 \pm 2.2, p<0.05$, respectively). Regional differences in thermal sensation were evident but were more prominent for females. Thermal sensation was greatest at the head then the torso and declined towards the extremities. In comparison to rest, exercise caused a significant reduction in thermal sensation for males ( $\Delta$ thermal sensation; $0.86 \pm 0.3, p<0.05$ ) but only at select locations in females $(0.31 \pm 0.56, \mathrm{p}>0.05)$.

Conclusion The data provides evidence that the thermal sensation response to warmth varies between genders and between body regions and reduces during exercise. These findings have important implications for clothing design and thermophysiological modelling.

Key words: Warm sensation, body mapping, gender, exercise, regional, thermal sensitivity

\title{
Abbreviations
}

BSA; Body surface area $\left(\mathrm{m}^{2}\right)$

$D_{b} ;$ total body density $(\mathrm{g} / \mathrm{cc})$

EIA; Exercise induced analgesia

$T_{b} ;$ Body temperature $\left({ }^{\circ} \mathrm{C}\right)$

$T_{c}$; Core temperature $\left({ }^{\circ} \mathrm{C}\right)$

TRPV; transient receptor potential vanilloid 
$T_{s k} ;$ Skin temperature $\left({ }^{\circ} \mathrm{C}\right)$

$\% \mathrm{BF}$; body fat percentage $(\%)$

\section{Introduction}

A large body of literature indicates a variety of gender linked differences in physiological responses to cold and heat exposure (Cunningham et al. 1978; Davies, 1979; Fournet et al. 2013; Havenith, 1997; Havenith 2001a;b; Havenith et al. 2008; Hensel, 1973; Smith and Havenith, 2011, 2012) yet research on thermal sensitivity tends to be limited to male participants (Nakamura et al., 2008; Ouzzahra et al. 2012; Stevens et al., 1974). Females have been shown to be more sensitive than males to a variety of stimuli (Fillingim et al. 1998; Otto and Doygher, 1985; Velle, 1987), yet there is a gap in the literature surrounding gender differences in innocuous thermal sensitivity. A common technique to measure thermal sensitivity is the method of limits (or threshold detection) in which participants respond to a stimulus once they feel a temperature change. Using this technique, Golja et al. (2003) and Lautenbacher and Strian (1991) aimed to investigate the temperature thresholds as an indicator of thermal sensitivity. Both studies found females to have a higher sensitivity for warmth and Golja et al. (2003) confirmed the same findings for cold. Research on gender differences has been limited to the threshold detection and gender differences have been found, but whether females are more sensitive to the degree of the sensation experienced (using magnitude estimation) in response to a fixed stimulus uncertain. Magnitude estimation is influenced by the difference between skin temperature and stimulus temperature and initial sensations are referred to as transient responses but if held for a given amount of time, they can reflect a steady state response to a given stimulus, removing the effect of the initial skin temperature ( $\left.T_{s k}\right)$ (Ouzzahra et al. 2012).

Studies on gender differences in thermal sensitivity have been limited to one or two body areas such as the forearm, hand and/or foot (Golja et al. 2003; Lautenbacher and Strian, 1991). Regional differences in regulatory functions of the human thermoregulatory system are well documented (Cotter and Taylor, 2005; Fournet et al. 2013; Hensel, 1973; Havenith et al. 2008; Nadel et al. 1973; Smith and Havenith, 2011, 2012) but further research is required to assess the sensory functions across more locations. Using magnitude estimation, Stevens et al. (1974) investigated regional sensitivity to the warmth by applying various warm stimuli (thermal irradiance) on up to 10 body regions on 18 male participants, resting in a neutral room $\left(21^{\circ} \mathrm{C}, 50 \% \mathrm{RH}\right)$. They determined regional differences in the following order of high to low sensitivity: forehead, cheek, chest, abdomen, shoulder, back, forearm, upper arm, thigh and calf. Despite a large number of receptors detected in the hands and feet (Strughold and Porz, 1931; Rein, 1935, both cited in Parsons, 2003, p.59; Jasper and Penfield, 1954), higher sensitivity has been reported by numerous researchers in the head and torso 
region (Arens et al. 2005a;b; Nadel et al. 1973; Nakamura et al. 2008; Stevens et al. 1974). Nakamura et al. (2008) speculated that the central nervous system assigns weighing factors for each body segment and that this is what determines the regional differences in sensitivity rather than receptor density. The weighing factors are related to basic functioning of temperature regulation which must maintain the temperature of the torso and head due to the vital organs located there (Nakamura et al. 2008).

Using the magnitude estimation method, Ouzzahra et al. (2012) recently assessed regional distribution of thermal sensitivity to cold during rest and exercise in male participants. Their methods involved the application of a fixed cold stimulus $\left(25 \mathrm{~cm}^{2}\right.$ thermal probe), set at $20^{\circ} \mathrm{C}$ on 16 body locations across the torso and arms. Regional differences in steady state perceptual responses were apparent, with the lateral areas of the abdomen and mid back being significantly more sensitive to the cold stimulus than medial areas of the torso. In addition, they found that thermal sensitivity at rest was significantly greater than during exercise at almost all regions measured. The reduction in thermal sensation to a cold stimulus was likely a result of exercise induced analgesia (EIA). EIA is associated with the activation of the endogenous opioid system during exercise in which various peptides are released that has a similar effect to that of morphine (i.e. they cause a reduction in pain sensitivity) (Beaumont and Hughes, 1979). Work in this field supports this theory as exercise has also been reported to cause a reduction in perceptual responses, particularly tactile and pain sensitivity (Guieu et al. 1992;

Kemppainen et al. 1986; Kemppainen et al. 1985; Pertovaara et al. 1984). Large amounts of research exist regarding EIA and pain sensitivity (Guieu et al. 1992; Kemppainen et al. 1986; Kemppainen et al. 1985; Pertovaara et al. 1984) but few studies have investigated thermal sensitivity.

As is evident from the above, thermal sensitivity has been studied in depth yet many questions remain unanswered. The most prevalent is the gender difference in magnitude sensation to a warm stimulus. Secondary to this is how exercise influences magnitude sensation and finally how this sensitivity varies across the body. Therefore, the aims of this investigation are to explore the regional differences in thermal sensitivity to a warm stimulus using magnitude estimation on both males and females during rest and exercise.

\section{Methods}

Participants

Twelve Caucasian males and twelve Caucasian females of similar fitness were recruited from the staff and student population of Loughborough University (see table 1 for participant characteristics). The selection criteria included only Caucasian males and females, aged between 18-45 years to reduce any 
systemic errors due to ethnic or age-related differences in thermoregulatory responses. Nine of the twelve female participants were taking oral contraceptives. Female menstrual cycle phase was not controlled for during the experimental session. However the stage of menstrual cycle in each participant was noted and a range of stages was tested during the experiment, thus providing a representative sample of menses state in the results.

\section{Experimental design}

The aim of the investigation was to compare sensitivity to a warm stimulus between the following: males versus females, rest versus exercise and regional variations across the body. To achieve these aims a repeated measures design was opted for, with males and females taking part in both rest and exercise (cycling) while regional thermal sensitivities to a thermal probe with a surface temperature of $40^{\circ} \mathrm{C}$ were investigated. A total of 31 regional body segments were chosen to ensure that each area of the body was fully investigated (detailed later). These included the front and back torso, the arms and legs (upper, lower, front and back), head, face and neck and the extremities. The testing sequence of the segments was balanced to prevent any order effects. However, the order of rest and exercise in the tests were not randomised as rest had to precede exercise due to the elevation of $T_{c}$ caused by the latter. This increase could have had a lasting effect in any following rest exposures. To counteract any order effect, participants were thoroughly familiarised with the procedure before the start of the actual test.

Experimental protocol

Each participant completed a pre-test session for anthropometric measurements; stature, body mass and skin folds thickness. For males, the 7-point caliper method (Jackson and Pollock, 1987) was used to measure skinfold thickness and the 4-point method for females (Jackson, Pollock and Ward, 1980). Different sum of skinfolds where used for males and females based on the accuracy of the estimation of body fat observed in different genders (Sinning and Wilson, 1984; Sinning et al. 1985). Sum of skin folds was used to estimate total body density $(D b)$ and then used to derive total percentage of body fat (\%BF) (Siri 1956, cited in Heyward and Wagner, 2004, p.7). Body surface area was calculated using the equation proposed by DuBois and DuBois (1916, cited in ACSM, 2005). They then completed a submaximal fitness test based on the Åstrand Rhyming methods (ACMS, 2005). The test comprised of four progressive exercise stages on an electromagnetically braked cycle ergometer (Lode Excalibur, Groningen, Netherlands) each lasting 5 minutes. Heart rate (Polar Electro

Oy, Kemple, Finland) was recorded during the last minute of each stage. Estimation of $\dot{\mathrm{VO}}_{2 \max }$ was then calculated from the ACSM metabolic equation for cycling (Franklin et al. 2000).

During the test, participants were familiarised with the thermal probe and sensation scales across a number of locations. Participants were then invited back to the laboratory on a different occasion to 
conduct the main trial. For the main trial, pre- and post-test nude weight was recorded. Participants self-inserted a rectal probe $10 \mathrm{~cm}$ beyond the anal sphincter. Four skin thermistors (Grant Instrument Ltd, Cambridge, UK) were attached at the chest, upper arm, thigh and calf using $3 \mathrm{M}^{\mathrm{TM}} \operatorname{Transpore}^{\mathrm{TM}}$ surgical tape, (3M United Kingdom PLC). Mean skin temperature $\left(\bar{T}_{s k}\right)$ was estimated using the following calculations as proposed by Ramanathan (1964):

$$
\bar{T}_{s k}=(0.3 * \text { Triceps })+(0.3 * \text { Chest })+(0.2 * \text { Quadriceps })+(0.2 * \text { Calf })
$$

Body temperature $\left(T_{b}\right)$ was estimated using the following calculations of $T_{c}$ and $\bar{T}_{s k}$ in an 8:2 ratio (Hardy and DuBois, 1938):

$$
T_{b}=0.8 * T_{c}+0.2 * \bar{T}_{s k}
$$

Markings were made on the body using a washable pen to indicate each measurement site for the application of the thermal probe. The locations of each stimulus application are shown in Figure 1. Dressed in shorts, socks and trainers (and sports bra for females) participants sat in a thermoneutral environment $\left(22.2 \pm 2.2^{\circ} \mathrm{C}, 35.1 \pm 5.8 \% \mathrm{RH}\right)$ for 15 minutes to allow physiological responses to stabilise. During the rest period participants were once again familiarised with the sensation scales and allowed to practise rating their sensations to a range of warm stimuli across different regions on the body.

After the rest period, thermal sensitivity of each body site along the left hand side of the body to a $40^{\circ} \mathrm{C}$ stimulus was investigated in a balanced order. Each stimulus site was subjected to the following: the measurement of local $T_{s k}$ using an infrared thermometer (FLUKE 566 IR THERMOMETER, Fluke Corporation, Eindhoven, Netherlands), immediately followed by probe application for 10 seconds. The temperature controlled thermal probe was similar to that described by Fowler et al. (1987) and Ouzzahra et al. (2012). The thermal probe (NTE-2, Physitemp Instruments, Inc, USA) consisted of a $25 \mathrm{~cm}^{2}$ metal surface that was controlled at $40^{\circ} \mathrm{C}$. The probe was applied to the skin by the same investigator to ensure consistent pressure was applied to each location and individual. The pen markings served as reference points for each location. Participants rated their thermal sensation after 10 seconds to indicate a steady state response; removing the effect of initial $T_{s k}$ has on the transient response (Ouzzahra et al. 2012). The thermal sensation scale was similar to that used by Ouzzahra et al. (2012) with 0 indicating 'no hot sensation' and 10 indicating 'extremely hot' with intermediary numbers. This scale was an adapted version of a scale for noxious heat stimulation (Casey and Morrow, 1984). From pilot testing, the stimulus site $T_{s k}$ was found to be similar to probe temperature after the 10 second application and thus the sensation reported indicated steady state magnitude sensation. For magnitude sensation, the higher the number reported the higher the sensitivity. 
Following the rest period, participants began cycling for 20 minutes at $50 \% \dot{V} O_{2 \max }$; after which the exercise intensity was lowered to $30 \% \dot{V} O_{2 \max }$ to ensure participants could maintain a high level of concentration on the thermal ratings whilst still exercising and to maintain an elevated but stable physiological state. The test was then repeated in the same order as the rest condition. Any sweat produced due to exercise was briefly wiped away before the probe was applied. During lower limb assessments, participants ceased exercise whilst the probe was applied and continued thereafter.

Data analysis

Statistical analysis was conducted using Statistical Package (SPSS) version 18.0. Differences in thermal sensation during rest and exercise across different body regions were analysed using threeway ANOVA with gender as a between subject factor and location $(n=31)$ and activity (rest and exercise) as repeated measures with post-hoc comparisons. The large number of locations increases the risk of inflating type I errors when doing multiple post-hoc zone comparisons therefore Bonferroni corrections were applied to adjust for this. However applying a conservative correction factor such as Bonferroni decreases the limit $\mathrm{P}$ value for significance to $<0.002$ and lower still for gender comparisons. This in turn would drastically increase the risk of a type II error. Therefore data corrected and uncorrected for multiple comparisons are presented to provide the reader insight in this issue (Havenith et al 2008). Unless otherwise stated, all measurements are expressed as means with standard deviations ( \pm S.D) and significance is defined as $\mathrm{p}<0.05$.

\section{Results}

Participant characteristics are displayed in Table 1. Independent samples t-tests revealed that males in comparison to females were significantly taller $(180 \pm 8.9 \mathrm{~cm}$ vs $167 \pm 5.7 \mathrm{~cm}, \mathrm{p}<0.05$, respectively), heavier (78.1 $\pm 15.6 \mathrm{~kg}$ vs $62.9 \pm 5.5 \mathrm{~kg}, \mathrm{p}<0.05$, respectively) and as such had a significantly larger body surface area $\left(55.8 \pm 6.5 \mathrm{~m}^{2}\right.$ vs $48.1 \pm 2.8 \mathrm{~m}^{2}, \mathrm{p}<0.05$, respectively). The \%BF was within the normal range for the respective genders, with females having a significantly higher $\% \mathrm{BF}$ than males. Fitness and age were not significantly different between genders.

Mean $T_{c}, T_{b}$ and $\bar{T}_{s k}$ of each condition are presented in Table 2. $T_{c}, T_{b}$ and $\bar{T}_{s k}$ did not significantly increase with exercise. There were no significant differences observed between genders. Mean gross sweat loss was $282.2 \pm 135.2 \mathrm{~g}$ for the males and $253.4 \pm 277.6 \mathrm{~g}$ for the females and they were not significantly different.

Gender differences in regional thermal sensitivity

Female and male magnitude thermal sensations are illustrated in Figure 2 and 3, respectively. A significant overall effect of gender was observed for sensations magnitude as females provided a 
warmer sensation score than males ( $4.7 \pm 1.8$ vs $3.6 \pm 2.2, \mathrm{p}<0.05$, respectively). A significant overall effect of location was observed $(\mathrm{p}<0.05)$ and a significant interaction between gender and location $(\mathrm{p}<0.05)$. Due to the large number of comparisons, the data was checked with and without Bonferroni corrections. No locations were found significantly different with Bonferroni corrections due to the extreme correction applied due to the large number of regions $(n=31)$ and limited number of participants. However, without corrections, the results revealed that all locations were sensed as significantly warmer for females than males $(\mathrm{p}<0.05)$. The regional differences are similar between genders, with the head and torso reported to be warmer (more sensitive) than the extremities.

When the effect of location was analysed for males and females separately, the results indicated no significant overall effect of location $(\mathrm{p}=0.4)$ for males but a significant overall effect for females $(p<0.05)$. Female pairwise comparisons are highlighted in Table 3. For females, there was little variation in sensitivity between zones of the head region; the cheek however was the only location in the head region to decline during exercise. All regions of the head scored a significantly warmer thermal sensation than areas within the legs ( $<<0.05$, without Bonferroni corrections). Overall the torso (posterior and anterior) rates a warmer thermal sensation than the extremities. Overall, no significant differences were observed within the anterior torso or within the posterior torso. The lateral aspect of the anterior torso had higher values than medial parts but this was not mirrored on the posterior torso. The extremities scored lower sensations than most locations of the head and torso region. At the arms the posterior aspects scored a warmer thermal sensation than the anterior, whilst the opposite is true of the legs. At the legs, sensation decreases proximal-distal as the upper legs generally scored a warmer thermal sensation than the lower legs. The lower legs scored a significantly lower thermal sensation than most locations across the body $(\mathrm{p}<0.05)$.

The influence of exercise on thermal sensitivity

A significant overall effect of activity was found as thermal sensation was warmer during rest than exercise ( $4.4 \pm 2.1$ and $3.9 \pm 2.0$, respectively, $\mathrm{p}<0.05$ ). The differences between rest and exercise for each location and the significant differences are displayed in Table 4; the larger the number the bigger the difference between rest and exercise. Negative numbers in Table 4 indicate where sensitivity increased with exercise, though none of these are significant $(\mathrm{p}>0.05)$. The males had the largest differences between rest and exercise and thus more significant differences (15 of 31 ) than the females ( 6 out of 31). In both groups, the largest differences between rest and exercise were at the lower legs $(\mathrm{p}<0.05)$. Regional differences that were observed in the females at the torso region tended to diminish with exercise.

\section{Discussion}


Three main findings can be drawn from this investigation; firstly, females had a stronger thermal warmth sensation (i.e. more sensitive) than males to a warm stimulus $\left(40^{\circ} \mathrm{C}\right)$. Secondly, regional variations in thermal sensation exist for both genders, but are more prominent for females. Thirdly, exercise caused a reduction in thermal warmth sensation to a hot thermal stimulus in males but only at select locations for females. These findings will be discussed in detail below.

\section{Gender differences}

Gender differences in thermoregulatory responses exist, particularly in response to heat stress (Cunningham et al. 1978; Davies 1979; Havenith 1997; Havenith 2001a:b; Havenith et al. 2008; Smith and Havenith 2012) but thermal sensitivity research is generally limited to male participants (Arens et al. 2005; Cotter and Taylor, 2005; Nakamura et al. 2008; Ouzzahra et al. 2012). The present study compared male and female thermal sensation to a $40^{\circ} \mathrm{C}$ stimulus and overall (mean of rest and exercise), females scored a significantly warmer thermal sensation than males ( $4.7 \pm 1.8$ vs $3.6 \pm 2.2$, $\mathrm{p}<0.05$, respectively). According to post hoc analysis, females were significantly more sensitive than males at all locations across the body ( $\mathrm{p}<0.05$, Figure 2 and Figure 3$)$. The findings add to the current body of literature surrounding the general concept of perception to a variety of stimuli between genders. Previous research has found females to be significantly more sensitive than males to heat using the method of limits (Golja et al. 2003; Lautenbacher and Strain, 1991; Kenshalo, 1986) and this study adds to the literature to confirm gender differences to heat using magnitude estimation. It has been suggested that body measures may correlate with the density of receptive units in the skin and thereby the number of stimulated afferent nerve fibres (Lautenbacher and Strain, 1991). Females had a significantly lower body surface area compared to males $\left(1.3 \pm 0.1 \mathrm{~m}^{2} \mathrm{vs} 1.6 \pm 0.2 \mathrm{~m}^{2}, \mathrm{p}<0.05\right.$, respectively) speculatively given a higher sensor density. However as the actual density and distribution of thermoreceptors on individuals of different sizes have not been directly measured in this study or that of Lautenbacher and Strain (1991), there is no supporting evidence for this hypothesis.

Across all conditions, $T_{c}, T_{b}$ or $T_{s k}$ did not significantly differ between genders or significantly increase due to exercise. Therefore the gender differences observed between males and females cannot be due to differences in the thermal state of the body. Paulson et al. (1998) also noted gender differences to 5 seconds of noxious $\left(50^{\circ} \mathrm{C}\right)$ and innocuous $\left(40^{\circ} \mathrm{C}\right)$ thermal stimuli. They claimed that these differences were indicative of different neural mechanisms that mediate thermal sensitivity between genders. Upon noxious heat stimulation $\left(50^{\circ} \mathrm{C}\right)$ females had a greater perception of pain than males which was also detected in a greater activation in the contralateral thalamus and interior insula (Paulson et al. 1998). Although not statistically significant they also found a similar trend for innocuous stimuli $\left(40^{\circ} \mathrm{C}\right)$. Reasons as to why females are more sensitive to noxious and innocuous stimuli as indicated by perceptual responses and neural mechanisms still remains unclear but we 
hypothesise that it is associated with behavioural thermoregulation. According to Inoue et al. (2005) females produce less sweat than males and rely upon convective heat loss more than evaporative heat loss. Therefore, it would be beneficial for females to be more sensitive to a heat stimulus than males in order to encourage behavioural responses to maintain thermal balance. With this in mind, these findings offer considerable evidence to support more gender specific testing in the areas of thermal sensitivity and behavioural thermoregulation. A large amount of research exists utilising male participants and often this data is applied to both genders, but data from the present study provides evidence to suggest that this is not appropriate.

Thermal pain sensitivity differences have consistently been found between males and females, which typically involves stimulating the noxious thermal pain receptors; TRPV1 $\left(>42^{\circ} \mathrm{C}\right)$ (Filingim et al. 1998; Lautenbacher and Strain, 1991; Paulson et al. 1998). The stimulus used in the present study $\left(40^{\circ} \mathrm{C}\right)$ was specifically chosen not to stimulate the TRPV1 family but rather TRPV3, which responds to temperatures $>33^{\circ} \mathrm{C}$. The findings of this study add to the growing body of literature that gender differences in thermal sensitivity not only occur in noxious stimulation (as shown by others; Filingim et al. 1998; Lautenbacher and Strain, 1991; Paulson et al. 1998) but also in innocuous stimuli as presented in this paper. But the reason for those gender differences requires further investigation. It is possible that a higher sensitivity to innocuous heat may act as a preventive measure against an increased heat load.

Regional differences

Regional variation in thermal sensitivity is evident (see Figure 2 and 3) and generally the pattern is similar between genders, but the analysis indicated a significant overall effect of location for females only $(\mathrm{p}<0.05)$. As far as we are aware this is the first study to report findings that females only demonstrated regional differences in thermal sensitivity, though this could also reflect a smaller difference in males and a limited statistical power of this sample size. At each location thermal sensation was always significantly higher for females than males $(\mathrm{p}<0.05)$. The following section on regional differences will focus upon female sensitivity, unless stated otherwise.

In agreement with the literature, the pattern over the body indicated a higher sensitivity at the head and the torso and the lowest at the extremities. For females the areas around the head were significantly more sensitive than a large number of other locations, but particularly those areas within the leg region $(\mathrm{p}<0.05)$. The head has consistently been defined as a sensitive area due to the large number of thermoreceptors and the importance of keeping the brain within a thermo-prescriptive zone (Cabanac, 1993; Nadel et al. 1973; Strughold and Porz, 1931, cited in Parsons, 2003 p59; Nagasaka et al. 1998). The torso also contains vital organs and research has shown this to be an area less sensitive than the face but more sensitive than the extremities for various other parameters than studied here (Arens et al. 2005; Cotter and Taylor, 2005; Havenith et al. 2008; Nadel et al. 1973; Nakamura et al. 
2008; Smith and Havenith 2012; Stevens et al. 1974). The findings from the present study are in agreement with the literature as areas within the front torso were significantly more sensitive than areas within the leg region $(\mathrm{p}<0.05)$. Both genders were more sensitive on the lateral aspects of the front torso compared to their respective medial parts (excluding the chest for females). Using the same methods but a cold stimulus $\left(20^{\circ} \mathrm{C}\right)$, Ouzzahra et al. (2012) found the lateral aspects of the torso to be more sensitive than the medial aspects. The lateral sites of the front torso can be particularly sensitive to touch and often described as ticklish areas. As the probe makes contact with the skin, it stimulates both thermoreceptors and mechanoreceptors simultaneously. The possibility of a 'dual' neural stimulus between mechanoreceptors and thermoreceptors of any region cannot be excluded, particularly in areas such as the lateral torso which may be more sensitive to touch.

A reduction in the distribution of thermoreceptors towards the extremities (Lee and Tamura, 1995; Strughold and Porz, 1931, cited in Parsons, 2003, pg59) will account for the sensitivity differences between the extremities and the torso and head. For the females the upper legs are more sensitive than the lower legs suggesting that sensitivity is in the order of proximal-distal, which is also supported by the head being more sensitive than the torso and the torso more sensitive than the extremities. During exercise, the opposite is true of the arms and hands as sensitivity increases from the hands towards the upper arm. Literature suggests that the hand is densely packed with various types of receptors yet only the females demonstrated a high sensitivity in this area compared to other locations across the body (Jasper and Penfield, 1954; Strughold and Porz, 1931; Rein, 1935, both cited in Parsons, 2003, p.59). Although using 'method of limits' Lautenbacher and Strian (1991) also found that females were more sensitive to a warm stimulus than males at the hand.

\section{Rest and exercise}

Exercise itself has been reported to cause a reduction in perception to a variety of stimuli, particularly tactile and pain sensitivity (Guieu et al. 1992; Kemppainen et al. 1986; Kemppainen et al. 1985; Pertovaara et al. 1984; Paalasmaa et al. 1991). This effect is referred to as EIA (exercise induced analgesia) in which neural and hormonal changes occur as a result of exercise (Koltyn, 2000). Ouzzahra et al. (2012) found that during exercise, thermal sensation to a cold stimulus decreased in comparison to at rest, which they associated with EIA. However, in their study, $T_{c}$ significantly increased from rest to exercise, which may have accounted for some of the changes in sensitivity between the two conditions. In the present study, $T_{c}$ did not significantly increase from rest to exercise for males (no change) or females $\left(+0.2^{\circ} \mathrm{C}, \mathrm{p}>0.05\right)$, yet thermal sensation was significantly cooler during exercise compared to rest $(4.4 \pm 2.1$ and $3.9 \pm 2.0$, $p<0.05)$. Therefore the reduction in thermal sensation could be a result of EIA. It has been reported that exercise induced stress hormones might play a key role in the reduction of somatic sensitivity by dynamic exercise (Janal et al. 1984; Kemppainen et al., 1985; Pertovaara et al., 1984). Circulating hormones were not monitored in the 
present study or by Ouzzahra et al. (2012) and future research is required see if they are accountable for a reduced sensitivity and determine any gender differences.

The majority of research associated with EIA has been associated with noxious stimulation. The current study adds to this body of literature as the stimulus was set purposefully so not to stimulate noxious heat $>42^{\circ} \mathrm{C}$, but close to the upper limits of innocuous heat $\left(40^{\circ} \mathrm{C}\right)$. This suggests that EIA is not limited to pain sensitivity but also affects innocuous thermal sensitivity. Table 4 shows the locations across the body that had significant changes in sensitivity from rest to exercise; the larger the number the bigger the difference between rest and exercise. The males displayed the greatest difference between rest and exercise and the differences were significantly greater than females $(0.86$ \pm 0.31 vs $0.31 \pm 0.56$, respectively, $\mathrm{p}<0.05$ ). Despite different methodologies (magnitude vs. method of limits), the forehead has frequently been reported as a thermosensitive area (Cotter and Taylor, 2005; Nadel et al. 1973; Stevens et al. 1974), which was also found using magnitude estimation in the present study. Interestingly though the results in Table 4 suggests that the sensitivity of the forehead is reduced with exercise so that it becomes similar to other sites within the facial area. Areas which displayed no significant differences between rest and exercise generally have a low sensitivity in comparison to other sites, suggesting that EIA is site specific or a given level of sensitivity is required for EIA to have an effect.

\section{Applications}

The application of these findings is important for the design of clothing, in particular sports clothing and protective clothing. The data can enhance the valuation of such clothing using thermal manikins, modelling of human thermophysiological responses, and climate control in cars or buildings in an attempt to avoid skin temperature fluctuations in areas sensitive to heat. It is now evident that previous research based on male participants regarding thermal sensitivity cannot be directly applied to both genders. Future research should consider gender specific testing in the areas of thermal sensitivity and behavioural thermoregulation.

\section{Limitations}

It is important to note that the duration of the stimulus was $10 \mathrm{sec}$ to achieve steady state scores and the surface area stimulated was the same across all locations $\left(25 \mathrm{~cm}^{2}\right)$; it is possible that a stimulation of varying durations and of different surfaces areas may results in different regional sensations reported by individuals. In addition the experiment was conducted under thermoneutral conditions $\left(22.2 \pm 2.2^{\circ} \mathrm{C}, 35.1 \pm 5.8 \% \mathrm{RH}\right)$ and responses may varying in hot and cold conditions as previously shown by Nakamura et al. (2008). Therefore the results discussed above are limited to the realms of this study. 


\section{Conclusions}

The findings from the present study confirm that females are more sensitive (i.e. reported warmer thermal sensation) to innocuous heat $\left(40^{\circ} \mathrm{C}\right)$ stimulation than males. In addition, females display more regional differences in thermal sensitivity than males, with the head being the most sensitive, followed by the torso and then the extremities. These finding are consistent with previous literature in the area. In addition, exercise causes a reduction in warmth sensation to a hot stimulus in males and females but this is only observed at select locations in females. In addition to this, thermosensitivity data based upon male participants should not be directly applied to the female population.

\section{Acknowledgements}

The authors would like to acknowledge the continued support from Oxylane Research during this study, in particular Dr. Sophie Herpin.

\section{Conflict of interest}

The present research was done in the context of an industry- co-funded $\mathrm{PhD}$ by Oxylane Research (Decathlon R\&D Department) and the Loughborough Design School (Environmental Ergonomics Research Centre). Bernard Redortier and Thomas Voelcker, members of the sponsoring industry (Oxylane Research), contributed to the conception and design of the experiment and contributed to the paper write-up. Nicola Gerrett and George Havenith were fully responsible for conducting the trials and the data analysis. The authors declare that they have no conflict of interest.

\section{References}

American College of Sport Medicine. (2005). ACSM's guidelines for exercise testing and prescription. (7th ed.) Lippincott Williams \& Wilkins, USA.

Arens EA, Zhang K, Huizenga, C (2005a). Partial- and whole body thermal sensations and comfort: Part II: Non-uniform environmental conditions. J Therm Biol 31: 60-66. doi:10.1016/j.jtherbio.2005.11.02

Arens EA, Zhang K, Huizenga, C (2005b). Partial and whole body thermal sensations and comfort; Part I: Uniform environmental conditions. J Therm Biol 31: 53-59. doi:10.1016/j.jtherbio.2005.11.027

Attia M, Engel P, (1982). Thermal pleasantness sensation: an indicator of thermal stress. Eur J Appl Physiol Occup Physiol 50: 55-70. Doi: 10.1007/BF00952244

Beaumont A, Hughes J, (1979). Biology of opioid peptides. Annu Rev Pharmacol 19: 245-267. 
Bullock J, Boyle J, Wang MB (2001). Physiology. (4th ed.) Lippincott Williams \& Wilkins, USA.

Cabanac M (1969). Plaisir ou deplaisir de la sensation thermique et homeothermie.[Pleasure or displeasure of the thermal sensation and homeothermy]. Physiol Behav 4:359-364.

Cabanac M (1993). Selective brain-cooling in humans:" fancy" or fact? The FASEB journal 7: 11431146.

Casey KL, Morrow TJ (1984). Arousal-related changes in the response of VP thalamic neurons to somatic and spinothalamic stimulation in the awake monkey. Pain 18: S313.

Chen C, Essick G, Kelly D, Young M, Nestor J, Masse B (1995). Gender-, side-and site-dependent variations in human perioral spatial resolution. Arch Oral Biol 40: 539-548.

Claus D, Hilz MJ, Hummer L, Neundörfer B (1987). Methods of measurement of thermal thresholds. Acta Neuro Scand 76: 288-296. doi: 10.1111/j.1600-0404.1987.tb03583.x

Cotter JD, Taylor NA (2005). The distribution of cutaneous sudomotor and alliesthesial thermosensitivity in mildly heat-stressed humans: an open-loop approach. J Physiol 565: 335-345.doi: 10.1113/jphysiol.2004.081562

Cunningham DJ, Stolwijk J, Wenger C (1978). Comparative thermoregulatory responses of resting men and women. J Appl Physiol 45: 908-915.

Davies CTM, (1979). Thermoregulation during exercise in relation to sex and age. Eur J Appl Physiol Occup Physiol 42: 71-79. doi: 10.1007/BF00421907

Fillingim RB, Maixner W, Kincaid S, Silva S (1998). Sex differences in temporal summation but not sensory-discriminative processing of thermal pain. Pain 75:121-127. doi: 10.1016/S03043959(97)00214-5

Fournet D, Ross L, Voelcker T, Redortier B, Havenith G, (2013). Body mapping of thermoregulatory and perceptual responses of males and females running in the cold. J Therm Biol 38:339-344. doi: 10.1016/j.jtherbio.2013.04.005

Fowler CJ, Carroll M, Burns D, Howe N, Robinson K, (1987). A portable system for measuring cutaneous thresholds for warming and cooling. J Neurol, Neurosur Ps 50: 1211-1215. doi:

10.1136/jnnp.50.9.1211 
Franklin BA, Whaley MH, Howley ET, Balady GJ (2000). ACSM's Guidelines for Exercise Testing and Prescription: Testing and Prescription Lippincott Williams and Wilkins, USA.

Gagge AP, Stolwijk JAJ, Hardy JD (1967). Comfort and thermal sensations and associated physiological responses at various ambient temperatures. Environ Res 1:1-20. doi: 10.1016/0013$\underline{9351(67) 90002-3}$

Golja P, Tipton, MJ, Mekjavic, IB (2003). Cutaneous thermal thresholds--the reproducibility of their measurements and the effect of gender. $J$ Therm Biol 28: 341-346.

Guieu R, Blin O, Pouget J, Serratrice G (1992). Nociceptive threshold and physical activity. Can J Neurol Sci 19: 69-71. doi: 10.1016/S0306-4565(03)00010-X

Hansson P, Backonja M, Bouhassira D (2007). Usefulness and limitations of quantitative sensory testing: clinical and research application in neuropathic pain states. Pain J Int Assoc Study Pain 129: 256-259. doi: 10.1016/j.pain.2007.03.030

Hardy JD, Dubois EF (1938). Basal metabolism, radiation, convection and evaporation at temperatures from $22^{\circ} \mathrm{C}$ to $35^{\circ} \mathrm{C}$. J Nutr 15: $477-492$.

Havenith G (1997) Individual heat stress response. Thesis, Nijmegen University, Ponsen and Looijen press, Wageningen, 1997. ISBN 90-9010979.

http://dare.ubn.kun.nl/bitstream/2066/18586/1/18586_indihestr.pdf

Havenith G (2001a). An individual model of human thermoregulation for the simulation of heat stress response. J Appl Physiol 90: 1943-1954. Retrieved from

http://www.jappl.org/content/90/5/1943.full.pdf + html

Havenith G (2001b). Human surface to mass ratio and body core temperature in exercise heat stress- a concept revisited. J Therm Biol 26: 387-393. doi: 10.1016/S0306-4565(01)00049-3

Havenith G, Fogarty A, Bartlett R, Smith C, Ventenat V (2008). Male and female upper body sweat distribution during running measured with technical absorbents. Euro J Appl Physiol 104: 245-255. doi: 10.1007/s00421-007-0636-z

Hensel H, (1973).Neural processes in thermoregulation. Physiol Rev 53: 948-1017.

Heyward VH, Wagner VR (2004). Body composition assessment. Human Kinetics, Champaign, IL, USA. 
Inoue Y, Tanaka Y, Omori K, Kuwahara T, Ogura Y, Ueda H (2005). Sex-and menstrual cycle-related differences in sweating and cutaneous blood flow in response to passive heat exposure. Euro J Appl Physiol 94: 323-332. doi: 10.1007/s00421-004-1303-2

Jackson AS, Pollock ML (1978). Generalized equations for predicting body density of men. Brit J Nutr 40: 497-504.

Jackson AS, Pollock ML, Ward A (1980). Generalized equations for predicting body density of women. Med Sci Sports 12: 175-182.

Janal MN, Colt EWD, Clark WC, Glusman M (1984). Pain sensitivity, mood and plasma endocrine levels in man following long-distance running: effects of naloxone. Pain 19:13-25. doi:

$\underline{10.1016 / 0304-3959(84) 90061-7}$

Jasper H, Penfield W (1954). Epilepsy and the Functional Anatomy of the Human Brain. $\left(2^{\text {nd }}\right.$ ed.) Little, Brown and Co, USA.

Kemppainen P, Pertovaara A, Huopaniemi T, Johansson G (1986). Elevation of dental pain threshold induced in man by physical exercise is not reversed by cyproheptadine-mediated suppression of growth hormone release. Neurosci lett 70: 388-392. doi: 10.1016/0304-3940(86)90585-9

Kemppainen P, Pertovaara A, Huopaniemi T, Johansson G, Karonen SL (1985). Modification of dental pain and cutaneous thermal sensitivity by physical exercise in man. Brain res 360: 33-40. doi: $\underline{0.1016 / 0006-8993(85) 91217-X}$

Kenshalo DR Sr. (1986). Somesthetic sensitivity in young and elderly humans. J Gerontol 41:732742 .

Koltyn KF (2000). Analgesia following exercise: a review. Sports Med 29: 85-98. doi: 10.2165/00007256-200029020-00002

Lautenbacher S, Strian F (1991). Sex differences in pain and thermal sensitivity: the role of body size. Atten, Percept Psycho 50: 179-183. doi: 10.3758/BF03212218

Lee U, Tamura T (1995). Distribution of cold sensitivity over human skin. Japan Society of Home Economics 46:1081.

Marks LE, Gonzalez RR (1977). Thermal sensation: perceived intensity and pleasantness related to skin temperature. Proceedings International Union of Physiology Sciences, Paris, 13, 480. 
Meh D, Deni`slic `M (1994) .Quantitative assessment of thermal and pain sensitivity. J Neurol Sci 127:164-169. doi: 10.1016/0022-510X(94)90069-8

Mohamed S, Srinavin K, (2005). Forecasting labor productivity changes in construction using the PMV index. Int J Ind Ergon 35: 345-351. doi: 10.1016/j.ergon.2004.09.008

Mower GD (1976). Perceived intensity of peripheral thermal stimuli is independent of internal body temperature. J Comp Physiol Psych 90: 1152-1155.

Nadel ER, Mitchell JW, Stolwijk JAJ (1973). Differential thermal sensitivity in the human skin. Pflüg Arch Euro J Physio, 340: 71-76.

Nagasaka T, Brinnel H, Hales J,Ogawa T (1998). Selective brain cooling in hyperthermia: the mechanisms and medical implications. Med hypotheses 50: 203-211. doi: 10.1016/S0306$\underline{9877(98) 90019-6}$

Nakamura M, Yoda T, Crawshaw LI, Yasuhara S, Saito, Y, Kasuga M, Nagashima, K, Kanosue, K (2008). Regional differences in temperature sensation and thermal comfort in humans. J Appl Physiol 105: 1897-1906. doi: 10.1152/japplphysiol.90466.2008

Otto MW, Dougher MJ (1985). Sex differences and personality factors in responsivity to pain. Percept motor skills 61: 383-390. Retrieved from http://www.amsciepub.com/doi/pdf/10.2466/pms.1985.61.2.383

Ouzzahra Y, Havenith G, Redortier B (2012). Regional distribution of thermal sensitivity to cold at rest and during mild exercise in males. $J$ Therm Biol 37: 517-523. doi: 10.1016/j.jtherbio.2012.06.003 Paalasmaa P, Kemppainen P, Pertovaara A (1991). Modulation of skin sensitivity by dynamic and isometric exercise in man. Eur J Appl Physiol Occup Physio, 62: 279-285. doi: 10.1007/BF00571553

Parsons KC (2003). Man and his thermal environment: the effects of hot, moderate, and cold environments on human health, comfort, and performance. (2nd ed.) London, UK: Taylor \& Francis.

Paulson PE, Minoshima S, Morrow TJ, Casey KL (1998). Gender differences in pain perception and patterns of cerebral activation during noxious heat stimulation in humans. Pain 76: 223-229. doi: $\underline{10.1016 / \mathrm{S} 0304-3959(98) 00048-7}$

Pertovaara A, Kojo I (1985). Influence of the rate of temperature change on thermal thresholds in man. Exp Neurol 87: 439-445. doi: 10.1016/0014-4886(85)90174-8 
Pertovaara A, Huopaniemi T, Virtanen A, Johansson G (1984). The influence of exercise on dental pain thresholds and the release of stress hormones. Physiol Behav 33: 923-926. doi: 10.1016/0031$\underline{9384(84) 90230-0}$

Ramanathan NL (1964). A new weighting system for mean surface temperature of the human body. $J$ Appl Physiol 19:531.

Sandby-Møller J, Poulsen T, Wulf H (2003). Epidermal thickness at different body sites: relationship to age, gender, pigmentation, blood content, skin type and smoking habits. Acta Dermo-Venereol 83: 410-413.

Schlader ZJ, Simmons SE, Stannard SR, Mundel T (2011a). The independent roles of temperature and thermal perception in the control of human thermoregulatory behavior. Physiol Behav 103: 217-224. doi: 10.1016/j.physbeh.2011.02.002

Schlader ZJ, Simmons SE, Stannard SR, Mundel T (2011b). Skin temperature as a thermal controller of exercise intensity. Eur J Appl Physiol 111:1631-9. doi: 10.1007/s00421-010-1791-1

Sinning WE, Dolny DG, Little KD, Cunningham LN, Racaniello A, Siconolfi SF, Sholes JL (1985). Validity of "generalized" equations for body composition analysis in male athletes. Med Sci Sports 17:124-130. Retrieved from http://www.setantacollege.com/wpcontent/uploads/Journal_db/Validity\%20of\%20composition.pdf

Sinning WE, Wilson JR (1984) Validity of "generalized" equations for body composition analysis in women athletes. Res Q Exercise Sport 55: 153-160. doi: 10.1080/02701367.1984.10608392

Smith CJ, Havenith G (2011). Body mapping of sweating patterns in male athletes in mild exerciseinduced hyperthermia. Eur J Appl Physiol 111: 1391-404. doi: 10.1007/s00421-010-1744-8

Smith CJ, Havenith G (2012). Body mapping of sweating patterns in athletes: A sex comparison. Med Sci Sports, Online First 2012; doi: 10.1249/MSS.0b013e318267b0c4

Ständer S, Luger TA (2009). Neuroreceptors \& Mediators. In: R.D. Granstein, \& T. Luger (Eds.), Neuroimmunology of the Skin (pp 13-23). Berlin: Springer-Verlag.

Stevens JC, Marks LE, Simonson DC (1974). Regional sensitivity and spatial summation in the warmth sense. Physiol Behav 13: 825-836. doi: 10.1016/0031-9384(74)90269-8 
Velle W (1987). Sex differences in sensory functions. Perspect Biol Med 30: 490-522.

Winslow CEA, Herrington LP (1949). Temperature and Human Life. Am J Public Health 40: $214-$ 215.

Zhang H, Huizenga C, Arens E, Wang D (2004) Thermal sensation and comfort in transient nonuniform thermal environments. Eur J Appl Physiol 92:728-733. doi: 10.1007/s00421-004-1137-y 
Table 1: Male $(\mathrm{n}=12)$ and female $(\mathrm{n}=12)$ characteristics (mean \pm SD). * Indicates significant difference between genders $(\mathrm{p}<0.05)$.

\begin{tabular}{lcccccc}
\hline & $\begin{array}{c}\text { Age } \\
\text { (years) }\end{array}$ & Mass (kg) & $\begin{array}{c}\text { Height } \\
(\mathrm{cm})\end{array}$ & BSA $\left(\mathrm{m}^{2}\right)$ & $\begin{array}{c}\dot{V} \mathrm{O}_{2 \max } \\
\left(\mathrm{ml} \cdot \mathrm{kg}^{-1} \cdot \mathrm{min}^{-1}\right)\end{array}$ & $\%$ BF \\
\hline Males & $20.6 \pm 1.0$ & $78.1 \pm 15.6^{*}$ & $180 \pm 8.9^{*}$ & $1.6 \pm 0.1^{*}$ & $34.3 \pm 5.2$ & $15.0 \pm 6.1^{*}$ \\
Females & $20.6 \pm 1.4$ & $62.9 \pm 5.5$ & $167 \pm 5.7$ & $1.3 \pm 0.1$ & $36.5 \pm 6.6$ & $22.0 \pm 4.2$ \\
\hline Mean & & & & & & \\
$( \pm \mathrm{SD})$ & $20.6 \pm 1.2$ & $70.5 \pm 13.8$ & $174 \pm 10.2$ & $1.4 \pm 0.2$ & $34.4 \pm 5.8$ & $18.5 \pm 6.2$ \\
\hline
\end{tabular}


Table 2: Mean $T_{c}, T_{b}$ and $\overline{\boldsymbol{T}}_{s k}( \pm \mathrm{SD})$ at rest and during exercise (inclusively) for males ( $\left.\mathrm{n}=12\right)$ and females $(n=12)$. No significant differences found.

Males Females

\begin{tabular}{lllll}
\hline & Rest & Exercise & Rest & Exercise \\
$\mathrm{T}_{\mathrm{c}}\left({ }^{\circ} \mathrm{C}\right)$ & $37.4 \pm 0.3$ & $37.4 \pm 0.5$ & $37.6 \pm 0.2$ & $37.8 \pm 0.2$ \\
$\mathrm{~T}_{\mathrm{b}}\left({ }^{\circ} \mathrm{C}\right)$ & $36.0 \pm 0.3$ & $36.1 \pm 0.5$ & $36.1 \pm 0.2$ & $36.2 \pm 0.2$ \\
$\bar{T}_{s k}\left({ }^{\circ} \mathrm{C}\right)$ & $30.2 \pm 0.7$ & $30.5 \pm 0.9$ & $30.0 \pm 0.2$ & $30.2 \pm 0.9$ \\
\hline
\end{tabular}


Table 3: The numbers correspond to the locations indicated in Figure 1 and the table shows the statistical findings from the pairwise comparisons of the females data $(+\mathrm{p}<0.1, \# \mathrm{p}<0.05, \dagger \mathrm{p}<0.001$, without Bonferroni corrections). No significant differences with Bonferroni correction.

\begin{tabular}{|c|c|c|c|c|c|c|c|c|c|c|c|c|c|c|c|c|c|c|c|c|c|c|c|c|c|c|c|c|c|c|}
\hline & 1 & 2 & 3 & 4 & 5 & 6 & 7 & 8 & 9 & 10 & 11 & 12 & 13 & 14 & 15 & 16 & 17 & 18 & 19 & 20 & 21 & 22 & 23 & \begin{tabular}{|l|}
24 \\
\end{tabular} & 25 & 26 & 27 & 28 & 29 & \begin{tabular}{|l|}
30 \\
\end{tabular} \\
\hline 2 & & & & & & & & & & & & & & & & & & & & & & & & & & & & & & \\
\hline 3 & & & & & & & & & & & & & & & & & & & & & & & & & & & & & & \\
\hline 4 & \# & \# & $\#$ & & & & & & & & & & & & & & & & & & & & & & & & & & & \\
\hline 5 & + & & & & & & & & & & & & & & & & & & & & & & & & & & & & & \\
\hline 6 & & & & & & & & & & & & & & & & & & & & & & & & & & & & & & \\
\hline 7 & & & & & & & & & & & & & & & & & & & & & & & & 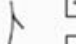 & 11 & & & & & \\
\hline 8 & + & + & $\#$ & & $\#$ & & & & & & & & & & & & & & & & & & & & & & 201 & & & \\
\hline 9 & & & & & & & & \# & & & & & & & & & & & & & & & & & & & $\frac{1}{22}$ & 17 & & \\
\hline 10 & & & & & & & & $\#$ & & & & & & & & & & & & & & & & & & & & & & \\
\hline 11 & & & & & & & & + & & & & & & & & & & & & & & & 2 & & & & $\sqrt{24}$ & & & \\
\hline 12 & & & & & & & & & & & & & & & & & & & & & & & Gow & & & & 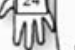 & & & \\
\hline 13 & & & & & & & & & & & & & & & & & & & & & & & & & & & & 28 & & \\
\hline 14 & \# & $\#$ & $\#$ & & & & & & & & & & & & & & & & & & & & & & 26 & & & 29 & & \\
\hline 15 & & & & & & & & + & & & & & & & & & & & & & & & & & & & & & & \\
\hline 16 & + & & & & & & & & & & & & & & & & & & & & & & & & & & & 30 & & \\
\hline 17 & & & & $\#$ & & & $\#$ & $\#$ & \# & & $\#$ & & & $\#$ & + & + & & & & & & & & & & & & & & \\
\hline 18 & & & & & & & & + & & & & & & $\#$ & & & & & & & & & & & & & & & & \\
\hline 19 & & & & + & & + & + & $\#$ & & & & & & + & & & & & & & & & & & & & & & & \\
\hline 20 & & & & & & & & & & & & & & $\#$ & & & & & & & & & & & & & & & & \\
\hline 21 & & & & + & & & & $\#$ & & & & & & \# & & & & & & & & & & & & & & & & \\
\hline 22 & & & & & & & & \# & & & & & & & & & & & & & & & & & & & & & & \\
\hline 23 & & & & & & & & + & & & & & & & & & + & & & & & & & & & & & & & \\
\hline 24 & & & & $\#$ & & & & $\#$ & & & & & & $\#$ & & + & & & & & & & & & & & & & & \\
\hline 25 & + & + & + & & & & & & & & & & & & & & & & & & + & & & & & & & & & \\
\hline 26 & & & & + & & + & & $\#$ & $\#$ & & & & & $\#$ & & + & & & & & & & & & + & & & & & \\
\hline 27 & & & & & & & & $\#$ & & & & & & \# & & & & & & & & & & & & & & & & \\
\hline 28 & & & & & & & & $\#$ & & & & & & \# & & & & & & & & & & & & & & & & \\
\hline 29 & + & & & & & & & & & & & & & & & & & & & & & & & & & + & & & & \\
\hline 30 & + & + & \# & & & & & & & & & & & & & & + & \# & + & \# & \# & & & \# & & \# & + & \# & & \# \\
\hline 31 & & & & & & & $\#$ & $\#$ & & & & & & & + & & & & & & & & & & & & & & & \\
\hline
\end{tabular}


Table 4: The differences in thermal sensation between rest and exercise for each location in females (first column) and males (second column). ${ }^{*} \mathrm{p}<0.05$ (without Bonferroni corrections). No significant differences with Bonferroni correction.

\begin{tabular}{|c|c|c|}
\hline \multirow[t]{2}{*}{ Location } & \multicolumn{2}{|c|}{$\begin{array}{c}\Delta \text { thermal sensation } \\
\text { (rest-exercise) }\end{array}$} \\
\hline & Females & Males \\
\hline Forehead & $-0.6 \pm 1.4$ & $0.9 \pm 0.9 *$ \\
\hline Cheek & $1.0 \pm 1.6$ & $0.7 \pm 0.7^{*}$ \\
\hline Anterior neck & $0.0 \pm 1.5$ & $0.4 \pm 1.4$ \\
\hline Posterior neck & $-0.3 \pm 1.7$ & $1.2 \pm 1.1^{*}$ \\
\hline Medial chest & $0.4 \pm 1.3$ & $0.7 \pm 1.2$ \\
\hline Lateral chest & $0.3 \pm 1.4$ & $0.3 \pm 1.3$ \\
\hline Medial torso & $0.3 \pm 1.4$ & $0.9 \pm 1.6$ \\
\hline Lateral torso & $0.8 \pm 1.1^{*}$ & $0.7 \pm 1.2^{*}$ \\
\hline Medial abdomen & $1.2 \pm 1.4^{*}$ & $1.1 \pm 1.9$ \\
\hline Lat abdomen & $0.4 \pm 1.5$ & $1.2 \pm 1.3^{*}$ \\
\hline Midaxillary & $-0.1 \pm 0.9$ & $1.4 \pm 2.2^{*}$ \\
\hline Suprailiac & $0.9 \pm 1.1^{*}$ & $0.5 \pm 2.2$ \\
\hline Upper medial back & $0.0 \pm 1.5$ & $1.4 \pm 1.9 *$ \\
\hline Scapula & $0.4 \pm 1.4$ & $0.8 \pm 1.3$ \\
\hline Middle medial back & $1.2 \pm 1.7^{*}$ & $1.4 \pm 1.2^{*}$ \\
\hline Middle lateral back & $0.7 \pm 1.4$ & $0.8 \pm 1.1$ \\
\hline Lower medial back & $0.5 \pm 1.2$ & $0.3 \pm 1.3$ \\
\hline
\end{tabular}




\begin{tabular}{|c|c|c|}
\hline Lower lateral back & $0.2 \pm 1.6$ & $1.0 \pm 1.1^{*}$ \\
\hline Biceps & $0.1 \pm 1.5$ & $1.0 \pm 2.0$ \\
\hline Triceps & $0.3 \pm 1.5$ & $0.9 \pm 1.0 *$ \\
\hline Anterior forearm & $0.3 \pm 1.5$ & $0.7 \pm 1.6$ \\
\hline Posterior forearm & $0.4 \pm 0.5^{*}$ & $0.3 \pm 1.6$ \\
\hline Palm & $-1.0 \pm 1.9$ & $0.8 \pm 1.5$ \\
\hline Back of hand & $-0.7 \pm 1.4$ & $0.7 \pm 0.8^{*}$ \\
\hline Quadriceps & $0.4 \pm 1.6$ & $0.3 \pm 1.3$ \\
\hline Front knee & $-0.4 \pm 1.4$ & $1.2 \pm 1.7^{*}$ \\
\hline Lateral gastrocnemius & $-0.1 \pm 1.0$ & $0.6 \pm 1.7$ \\
\hline Hamstring & $0.5 \pm 1.2$ & $1.0 \pm 1.4^{*}$ \\
\hline Posterior knee & $0.1 \pm 1.3$ & $0.9 \pm 1.7$ \\
\hline Post. gastrocnemius & $0.9 \pm 1.2^{*}$ & $1.21 .6^{*}$ \\
\hline Medial gastrocnemius & $1.4 \pm 1.6^{*}$ & $1.5 \pm 1.6^{*}$ \\
\hline Mean & $0.31 \pm 1.5$ & $0.86 \pm 0.1 .4^{*}$ \\
\hline
\end{tabular}




\begin{tabular}{|l|l|}
\hline$\#$ & Location \\
\hline 1 & Forehead \\
\hline 2 & Cheek \\
\hline 3 & Anterior Neck \\
\hline 4 & Medial Chest \\
\hline 5 & Lateral Chest \\
\hline 6 & Medial torso \\
\hline 7 & Lateral torso \\
\hline 8 & Medial Abdomen \\
\hline 9 & Lateral Abdomen \\
\hline $10 *$ & Midaxillary \\
\hline $11 \#$ & Suprailiac \\
\hline 12 & Posterior Neck \\
\hline 13 & Upper Medial Back \\
\hline 14 & Scapula \\
\hline 15 & Middle Medial Back \\
\hline & \\
\hline
\end{tabular}

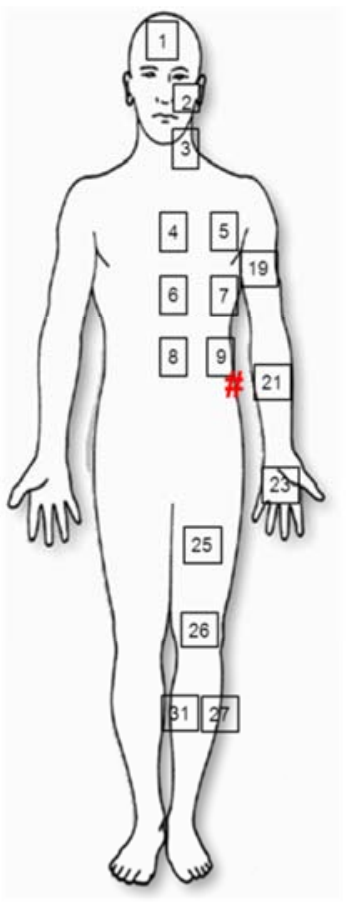

\section{\# $\quad$ Location}

16 Middle Lateral Back

17 Lower Medial Back

18 Lower Lateral Back

19 Bicep

20 Triceps

21 Anterior Forearm

22 Posterior Forearm

23 Palm

24 Back of Hand

25 Quadriceps

26 Front of Knee

27 Lateral Gastrocnemius

28 Hamstring

29 Posterior Knee

30 Posterior Gastrocnemius

31 Medial Gastrocnemius

Figure 1: Number, name and location of the 31 body sites investigated for thermal sensitivity. Location number 10 and 11 are donated on the figure by symbols * and \#, respectively. 


\section{Rest}

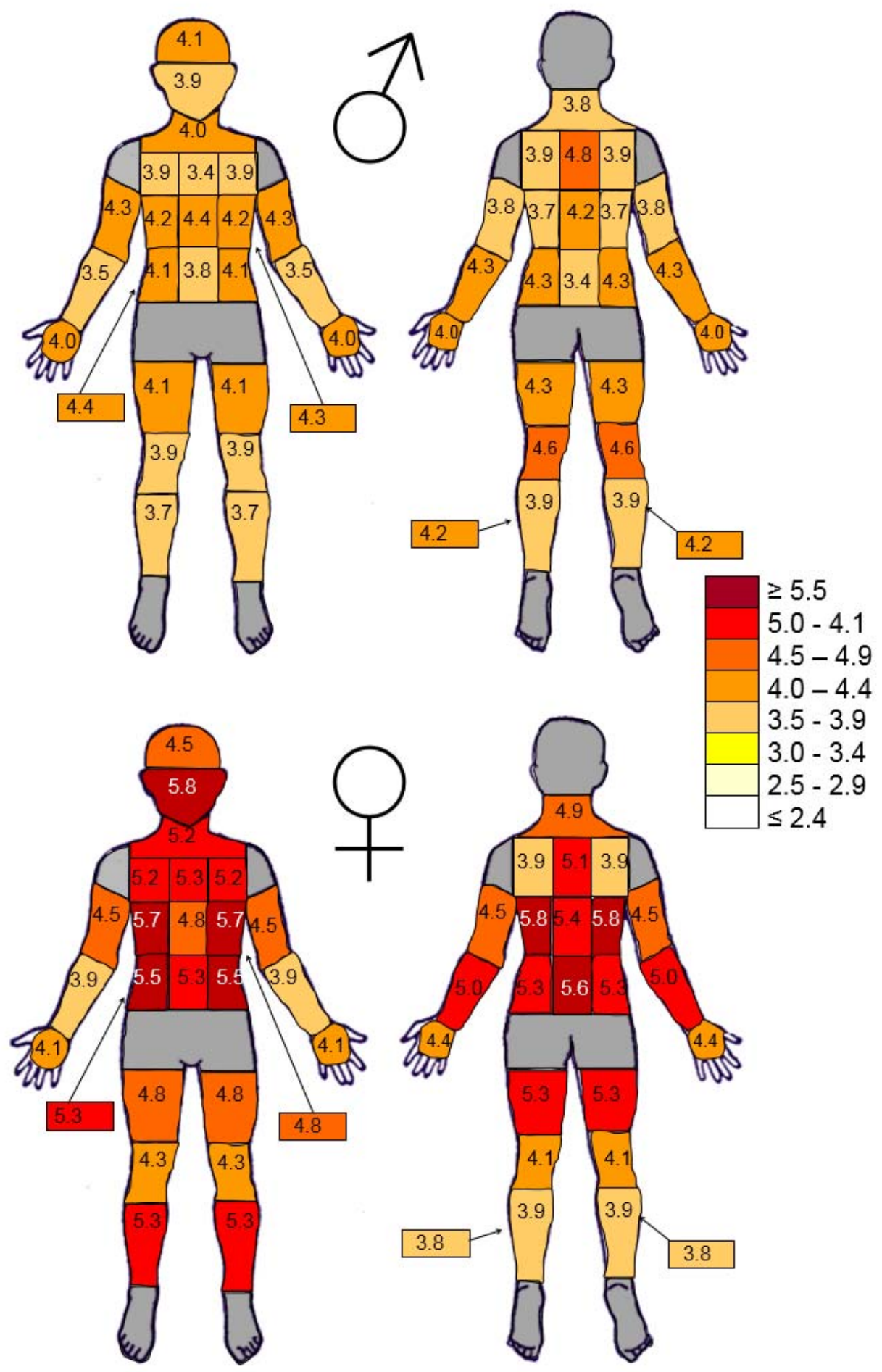

Figure 2: Male $\left({ }^{\lambda}\right)$ and female $(+)$ regional magnitude sensation to a warm stimulus $\left(40^{\circ} \mathrm{C}\right)$ during rest. All female locations were significantly warmer than males $(\mathrm{p}<0.05)$. All measurements were taken from the left hand side of the body but for presentation symmetry was assumed (Claus et al. 1987; Meh and Deništič, 1994). Areas in grey were not investigated. A value of 0 indicated 'no hot sensation' and 10 indicated 'extremely hot' with intermediary numbers 


\section{Exercise}
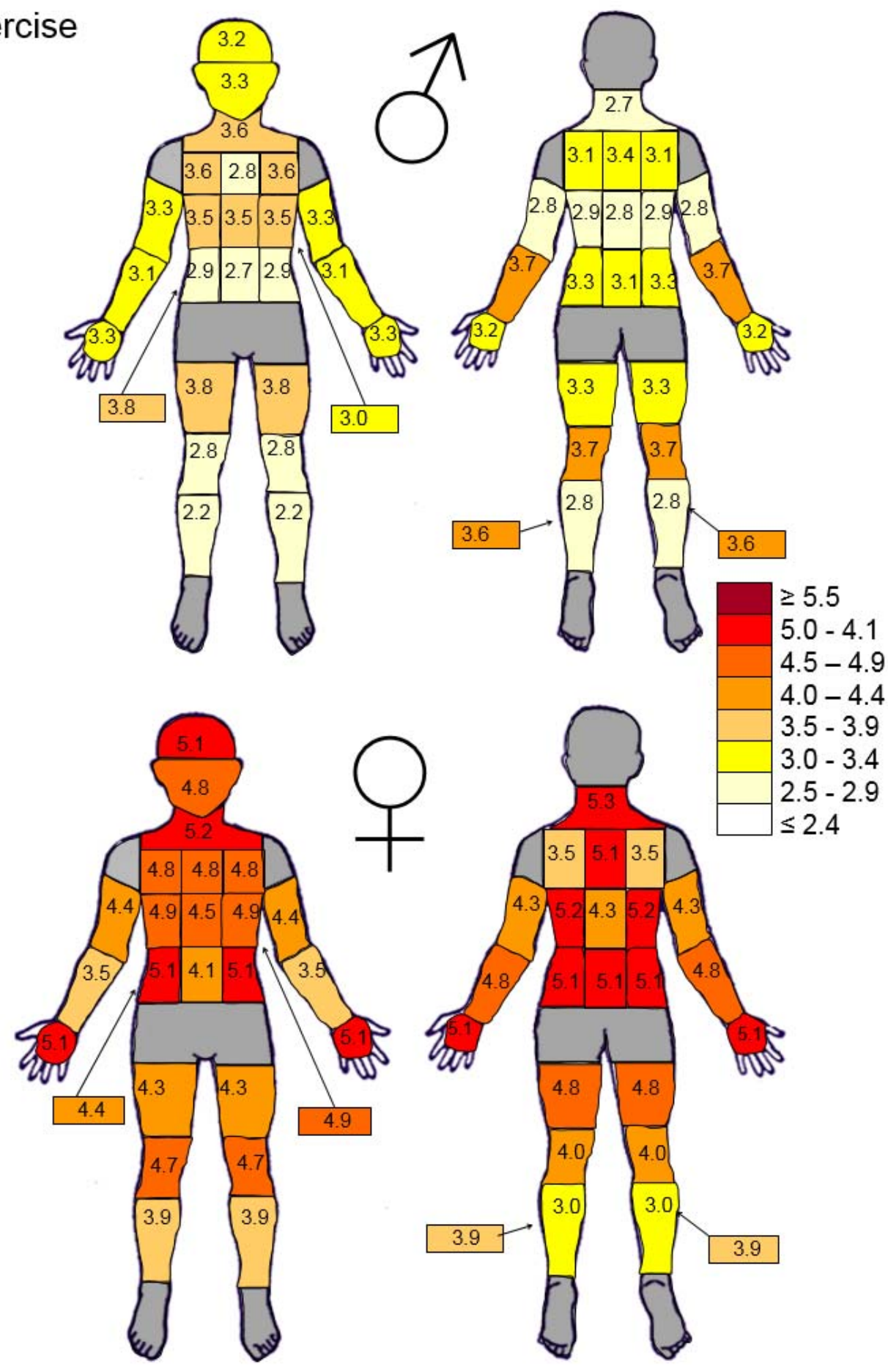

Figure 3: Male $\left({ }^{\Uparrow}\right)$ and female $(\stackrel{+}{)})$ regional magnitude sensation to a warm stimulus $\left(40^{\circ} \mathrm{C}\right)$ during exercise. All female locations were significantly warmer than males $(\mathrm{p}<0.05)$. All measurements were taken from the left hand side of the body but for presentation symmetry was assumed (Claus et al. 1987; Meh and Deništič, 1994). Areas in grey were not investigated. A value of 0 indicated 'no hot sensation' and 10 indicated 'extremely hot' with intermediary numbers 